\title{
Programming for HIV prevention in South African schools: A report on program implementation
}

Priscilla Reddy

Shegs James

Ann P. McCauley

Follow this and additional works at: https://knowledgecommons.popcouncil.org/departments_sbsr-hiv

Part of the Demography, Population, and Ecology Commons, Health Policy Commons, Immune System Diseases Commons, International Public Health Commons, Medicine and Health Commons, Public Health Education and Promotion Commons, Social Policy Commons, and the Virus Diseases Commons

How does access to this work benefit you? Let us know!

\section{Recommended Citation}

Reddy, Priscilla, Shegs James, and Ann P. McCauley. 2005. "Programming for HIV prevention in South African schools: A report on program implementation," Horizons Final Report. Washington, DC: Population Council. 


\section{Programming for HIV Prevention in South African Schools: \\ A Report on \\ Program Implementation}

\section{Hgrizons N}
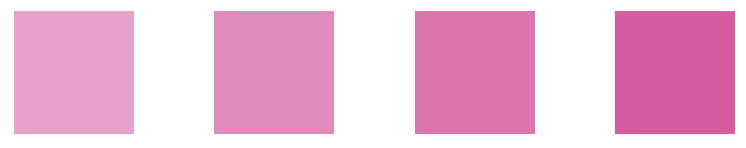

Health Promotion Research and

Development Unit, Medical Research Council, Cape Town

Horizons Program 


\title{
Programming for HIV Prevention in South African Schools: A Report on Program I mplementation
}

\author{
Priscilla Reddy and Shegs J ames \\ Health Promotion Research and Development Unit, \\ Medical Research Council, Cape Town, South Africa \\ Ann McCauley \\ Horizons/International Center for Research on Women, \\ Washington, DC, USA
}




\section{Acknowledgments}

We would like to thank the following institutions and individuals:

- The Department of Education for consent to evaluate the implementation of the school, program, and the teachers, learners, and parents of the Midlands and Richmond districts.

- Prof. B. van den Borne and Dr. R. Ruiter of the University of Maastricht, the Netherlands, for statistical support and interpretation of data analysis.

- Prof. C. C. Jinabhai and Dr. M. Taylor of the Nelson R. Mandela School of Medicine, for review of earlier drafts.

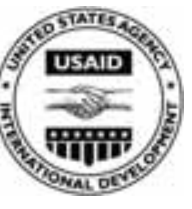

This study was supported by the Horizons Program, which is implemented by the Population Council in collaboration with the International Center for Research on Women, International HIV/AIDS Alliance, PATH, Tulane University, Family Health International, and Johns Hopkins University. Horizons is funded by the President's Emergency Plan for AIDS Relief through the U.S. Agency for International Development, under the terms of HRN-A-00-97-00012-00. The opinions expressed herein are those of the authors and do not necessarily reflect the views of the U.S. Agency for International Development.

Published in December 2005.

\section{(P) Population Council} The Population Council is an international, non-profit, nongovernmental institution that seeks to improve the well-being and reproductive health of current and future generations around the world and to help achieve a humane, equitable, and sustainable balance between people and resources. The Council conducts biomedical, social science, and public health research and helps build research capacities in developing countries. Established in 1952, the Council is governed by an international board of trustees. Its New York headquarters supports a global network of regional and country offices.

Copyright (C) 2005 The Population Council Inc.

Suggested citation: Reddy, Priscilla, Shegs James, and Ann McCauley. 2005. "Programming for HIV prevention in South African schools: A report on program implementation,” Horizons Final Report. Washington, DC: Population Council.

This document may be reproduced in whole or in part without permission of the Population Council provided full source citation is given and the reproduction is not for commercial purposes.

Horizons Program/Population Council

Communication Unit

4301 Connecticut Ave, NW, Suite 280

Washington, DC 20008

horizons@pcdc.org
Horizons Program/Population Council

P.O. Box 411744

Craighall 2024

Johannesburg, South Africa

horizons@pcjoburg.org.za 


\section{Table of Contents}

Executive Summary

Introduction 5

School-based programs $\quad 5$

$\begin{array}{ll}\text { Study aims } & 7\end{array}$

Hypothesis $\quad 7$

Description of the Life Skills Programme $\quad 7$

Research methodology $\quad 8$

Study participants and setting $\quad 9$

Sampling and phases of study $\quad 9$

$\begin{array}{ll}\text { School allocation and learner drop out } & 10\end{array}$

$\begin{array}{ll}\text { Study instrument and outcome measures } & 10\end{array}$

$\begin{array}{ll}\text { Demographic profile of learners } & 13\end{array}$

Results $\quad 15$

$\begin{array}{ll}\text { Sexual activity } & 15\end{array}$

$\begin{array}{ll}\text { Knowledge } & 19\end{array}$

$\begin{array}{ll}\text { Relationships } & 20\end{array}$

Attitude toward people living with HIV/AIDS 22

Male and female learners had different needs and outcomes 23

Learners' Perceptions of the Program 25

Program was educational and useful 25

Increased confidence and communication about HIV/AIDS 25

Minority of learners had mixed reactions $\quad 26$ 
Teachers Experiences and Suggestions

$\begin{array}{ll}\text { Teacher selection and characteristics } & 28\end{array}$

$\begin{array}{ll}\text { Training components and effectiveness } & 28\end{array}$

$\begin{array}{ll}\text { Teachers' satisfaction and challenges } & 30\end{array}$

Conclusions and Recommendations $\quad 32$

Programmatic recommendations for teacher preparation and support 32

Programmatic recommendations to address the needs of learners 33

References $\quad 34$ 


\section{List of Tables and Figures (in order of appearance)}

Table $1 \quad$ Sociodemographic profile of respondents at baseline

Figure $1 \quad$ Learners' reported sexual activity at T1 and T2

Figure 2 Intervention group's learners' report of intended sexual activity in the next three months

Figure 3 Percentage of youth who plan to have sex with a condom in the next three months

Figure $4 \quad$ Percentage of students who believe teenagers should be abstinent

Figure 5 Mean number of correct answers for learners on knowledge section about HIV/AIDS

Table 2 Percentage of learners answering knowledge questions correctly at T1 and T2

Figure 6 Learners' beliefs about the repercussions of girls not engaging in sexual activity with their boyfriend

Figure 7 Learners' attitudes toward forced sex

Figure 8 Learners' attitudes toward an HIV-positive classmate

Figure 9 Learners' attitude toward an HIV-positive teacher

Figure $10 \quad$ Confidence to talk about sexual issues with my...

Figure 11 Learners discussed Life Skills Programme with...

Table 3 Reported teacher coverage of program topics 



\section{Executive Summary}

As national education programs incorporate HIV prevention into school curricula, policymakers and educators need to know what they can expect from these initiatives. An evaluation study conducted in KwaZulu Natal, South Africa, provides important insights into whether learners that participated in a fact-based, interactive course had more knowledge about HIV risks, prevention, and care practices; more positive attitudes toward prevention practices and people living with HIV and AIDS; and a higher prevalence of reported safe behaviors than comparable learners who did not participate in the course.

The Medical Research Council of South Africa and the Horizons Program studied the Life Skills Grade 9 curriculum, a school-based HIV/AIDS program, as it was introduced in the Pietermaritzburg region of KwaZulu Natal Province in 2001. The 16-hour Grade 9 curriculum was taught at least once a week in the second and third quarters as part of the subject, "Life Orientation."

The study used a quasi-experimental research design that included surveying teachers and students over time. Twenty-two schools participated: 11 of the schools in which the course was first introduced served as intervention schools, and 11 where the course had not been taught served as control schools. To measure the effectiveness of the program among students, a pre-test, multiple post-test control group design was used. Students completed the surveys at baseline (T1), immediately after the course was finished (T2), and four months later (T3). Teachers' impressions of the program were also determined from a questionnaire they answered at the completion of the program.

\section{Key Findings}

\section{The program did not increase sexual activity.}

After the course more students in both the control and intervention groups had had sexual intercourse, but those who participated in the program were slightly less likely to have done so than those in the control group (36 percent vs. 37 percent).

\section{Youth go through periods of abstinence despite having initiated sexual activity.}

When asked about having sex during the six-month recall period, less than 60 percent of sexually experienced males and females reported that they had had sex. 


\section{Intention to have sex did not increase among learners.}

At baseline more than two-thirds of the students in both control and intervention groups did not intend to have sexual intercourse, and a similar proportion maintained this intention to remain abstinent after the course and four months later. Consequently, the proportion of those students who intended to have sex remained stable. However, after the course, a significantly greater proportion of learners in the intervention group intended to use a condom instead of having unprotected sex compared to those in the control group (33 percent vs. 23 percent; $p<.009$ ).

\section{Approval of teenage abstinence increased within the intervention group, particularly among males.}

Students were asked if they believed that it is a good idea not to have sex while a teenager. Sixtyone percent of intervention males and more than seventy-five percent of intervention females supported abstinence among teenagers at baseline. For both groups there was a statistically significant increase in the proportion that agreed with the statement at T2 (males: $p<.001$; females: $\mathrm{p}<.05$ ) and this was maintained for both groups at T3. In contrast, support for abstinence among the control group was less at T2 and T3 compared to T1.

\section{Learners in both the control and intervention groups increased their understanding that abstinence protects from HIV.}

At baseline 66 percent and 63 percent of learners in the control and intervention groups understood that abstinence protects from HIV. These proportions steadily increased between both groups over time, suggesting that messages outside of the program were influencing students' knowledge.

\section{Young men reduced their number of sex partners slightly.}

Males in the intervention group reduced their number of sexual partners more than the control group, but this difference was not statistically significant.

\section{Students had high levels of knowledge, and the program improved these levels further.}

At baseline both control and intervention learners had a mean score of 13 correct answers out of 15 on a questionnaire about HIV/AIDS. As a result of participating in the course, the mean number of correct answers increased for intervention learners while the mean remained largely unchanged for the control learners. 


\section{Youth already had some positive attitudes and behaviors.}

This study revealed that at baseline, the vast majority of male and female learners did not support sexual coercion of girls by boys, and 85 percent of learners who had sex in the last six months reported using a condom. Life skills programs should reinforce already existing positive attitudes and behaviors.

\section{There were positive trends among youth in both the control and intervention groups.}

When comparing the responses of the control and intervention groups, it was clear that on some measures, both groups of learners made improvements. This finding suggests that there are other sources of information and communication about HIV that positively affected all of the young people who were surveyed.

\section{Male and female learners had different needs and different outcomes.}

The data indicate that males and females had different needs going into the course and that the course impacted them differently on some measures. This was particularly true with regard to sexual behavior and attitudes toward sexual behavior.

\section{Teachers focused on HIV/AIDS information rather than on life skills.}

The teachers focused their teaching on the sections of the curriculum that covered information about HIV/AIDS. They gave less attention to the life skills components of the course and to caring for people living with HIV/AIDS.

\section{Learner interest made teaching rewarding.}

When asked what was most satisfactory about teaching these sessions, most teachers mentioned learner interest and the importance of the topic of HIV/AIDS.

\section{Teaching about sensitive topics presented special class management issues.}

Teachers reported several challenges to teaching the course. These included feeling unsure about details of some topics, drawing some learners into classroom discussion, dealing diplomatically with learners' beliefs about HIV/AIDS, and managing those learners that felt HIV/AIDS was not something that affected them. 


\section{Teachers need more information, training, and technical support.}

Most teachers requested more factual information about HIV/AIDS and preferred that a health expert address this aspect.

\section{Conclusions and Recommendations}

The Life Skills Grade 9 Curriculum had a positive impact of students' knowledge of HIV/AIDS, attitudes about abstinence, and intention to use condoms. These effects are important for laying the groundwork for behavior change that will protect young people from HIV/AIDS. There was, however, no evidence of increased adoption of such protective behaviors as abstinence and condom use. This may be because the teachers did not focus as strongly on the life skills components as on the factual HIV/AIDS information. Moreover this was the first time that the teachers had taught this particular curriculum. Their skills, comfort level, and effectiveness are likely to improve with experience. The following recommendations emerged from the study and aim to improve teacher preparation and support, and the overall program:

- Choose and train teachers who are committed to the program.

As indicated by this study, being able to meet the learners' needs enhances teachers' feelings that they are "doing something" important and contributes to their sense of satisfaction. The choice of appropriate teachers therefore will always be crucial to the successful implementation of a life skills program focusing on HIV and AIDS.

\section{- Provide teachers with moral, material, and technical support.}

Ongoing training, provision of updated materials and information, access to and liaisons with health professionals, and a forum to interact about the strengths and challenges of such a program need to be in place to ensure support to teachers.

- Ensure dedicated time and teachers to implement the program.

The findings reflect that time and adequately prepared teachers are both needed to foster positive program results.

\section{- Provide a program that teaches skills as well as information, and addresses the different needs of learners.}

The findings indicate that most learners in this study context were adequately prepared with information about HIV and AIDS. However, such information needs to be reinforced and complemented by skills building to create changes on several variables, such as resisting peer pressure, talking to a partner about sex and taking steps to prevent HIV infection, including abstaining from sex, and negotiating and using condoms. Learner differences also need to be taken into account, since all learners are not the same sex and age, they are not all sexually active, nor do they have the same knowledge and perceptions about HIV and AIDS issues. 


\section{Introduction}

A document published by UNAIDS (2000) describes the seriousness of the AIDS epidemic in the Southern African region, and highlights South Africa as being the most affected country. A national HIV seroprevalence study conducted at antenatal clinics in public health facilities showed that 22.4 percent of pregnant women were infected with HIV, and for all South Africans, the prevalence rate was 12.5 percent. The antenatal survey demonstrated that the age group most affected by the epidemic were women in their twenties; HIV prevalence among 20- to 24-year-old women was 25.6 percent, and for the 25 to 29 year old age group, the figure was 26.4 percent. HIV prevalence among women less than 20 years old was 16.5 percent (Department of Health 2000a).

The South African government has responded in a comprehensive manner to the AIDS epidemic. The National AIDS Plan provides guidance for addressing the epidemic on several levels, including primary prevention interventions, such as school-based programs, early detection of HIV infection through voluntary testing and counseling, and, at the patient-care level, various forms of individual and community-based care.

One important initiative developed by various government departments is the Integrated Plan for Children Infected and Affected by HIV/AIDS. A component of this initiative is the youth program which addresses issues affecting youth in and out of school. This program calls on the Departments of Health, Welfare, and Education to coordinate their efforts and work in an integrated manner to manage the HIV/AIDS epidemic with regard to children and youth (Department of Health 2000b).

Six components were outlined in the plan, two of which discuss the introduction of life skills programs in schools and the development of policies and strategies for the care of orphans and, through home-based care models, the care of people living with HIV. This call was supported by the Department of Education and is outlined in the National Education Act, 1996. The act stipulates that school governing bodies, acting within their functions under the South African Schools Act, 1996, shall give operational effect to the national policy by developing and adopting an HIV/AIDS implementation plan that would reflect the needs, ethos, and values of a specific school or institution and its community (Government of South Africa 1999). The Department of Education further supported its call for continuing life skills and HIV/AIDS education through the development and distribution of the "Tirasano/Working Together" document that provided guidelines for educators on HIV/AIDS.

\section{School-based Programs}

Since their inception, school-based sexuality programs in South Africa have been fraught with problems. The introduction of sexuality programs, known as "family life education," began long before the reorganization of government as a result of the transition from apartheid to democracy in 1994. The five different education departments, representing the racially segregated system under which education was being delivered, were responsible for program implementation. Due to differences in resource allocation, the programs varied widely in quality, structure, and delivery. A 


\section{Hgrizons}

review of school-based education programs in KwaZulu Natal (KZN) by Varga and Shongwe (1999) identified several reasons for the failure of programs:

- Unequal allocation of resources among the education departments.

- Lack of system-level support for school-based sexuality education.

- Inadequate preparation and training of teachers.

- Lack of community and system-level resources for education follow-up.

- Reliance on NGOs and other external agencies.

- Lack of programmatic evaluation.

Both prior to and after the end of apartheid in South Africa, considerable efforts were undertaken to make changes to the education structure. There was a call for strategies to provide equal education for all South Africans. The emphasis for learning was to shift from being "memorization of facts and evaluation through examination performance" to "accruing knowledge and experience, and evaluation through students' achievement of specified levels of functioning or outcomes." This emphasis is reflected in the document Curriculum 2005 (National Department of Education 1997), which has life orientation as one of its eight learning areas. It is within the sessions allotted to the life orientation learning area that the issues of life skills and sexuality education are to be addressed.

At the same time, increasing prevalence of HIV among young people resulted in an increase in sexuality education focused on HIV/AIDS education. In 1997 the National Department of Education launched a program to train two teachers from every secondary school in the country about HIV/AIDS. This was implemented differently in each of the nine provinces in terms of who did the training, what was done, and the extent to which the program was implemented at the school level.

Evaluation of the program in KZN showed that the process was slowed at the beginning by a delay in funds from the national government. This resulted in the program not being implemented as set out in the business plan (Markham 1998). In addition, a crisis in education as a result of redeployment of teachers gave rise to a lot of uncertainty and disruption within the school system, which contributed to poor implementation of the program.

In addition to the bleak scenario, the impact of the HIV/AIDS epidemic is becoming more visible and, in the absence of a medical cure, implementation of an effective sexuality program has become a matter of urgency. Moreover, the school setting provides an opportunity for primary prevention of HIV infection among large numbers of potentially vulnerable young peoplenumbers that have increased because of the introduction of free education. Current figures indicate that there are 1,734,210 primary and 867,330 secondary school learners in KZN (Department of Health 2000b). 


\section{Study Aims}

The aims of the study were to:

- Evaluate the impact of a school-based HIV prevention program on the knowledge, skills, attitudes, and behaviors of students.

- Assess the impact of teacher training on teachers' HIV-related knowledge and attitudes, and on their confidence and comfort in teaching the course.

- Identify teachers' experiences in implementing the course.

\section{Hypothesis}

The study's hypothesis was that students who participate in a fact-based, interactive life skills program, when compared to comparable students who do not participate in the course, will have:

- Greater knowledge about HIV risks, prevention, and care practices.

- More positive attitudes toward safer sex practices and people living with HIV and AIDS.

- Higher prevalence of safe behaviors.

\section{Description of the Life Skills Programme}

The KwaZulu Natal Department of Education's Life Skills Programme aims to reduce the prevalence of HIV among students. The program is being carried out in three phases, targeting a percentage of schools in each phase. By the end of phase three (after 3 years), all schools will have a trained teacher(s) on site to coordinate the program at their respective school. For each primary school, one teacher for grades 5, 6 and 7, will be trained. For secondary school, two teachers for grades 8 and 9 will be trained. The program includes the following elements:

- Master training.

- Teacher training.

- Implementation with learners.

- Training of peer educators.

- Motivational workshops for middle management, members of the school governing body, parents, traditional leaders, and healers.

- Ongoing support and workshops with trained educators.

- Ongoing collaboration with other role-players and partners in the integrated plan (Departments of Health and Social Services).

- Ongoing monitoring and evaluation of program implementation.

This study focused on evaluating the teacher training component and the impact of the curriculum as implemented by the trained teachers on learners. Although the program includes other elements, some of these, such as peer education, were not carried out in the schools in the study sites. 


\section{Hgrizons}

As part of the study, 37 program coordinators from the Department of Education underwent training in January 2001 by specially hired service providers to become master trainers. These master trainers were then responsible for training the teachers and monitoring the implementation of the program by the teachers. The master trainers conducted site visits to deliver material, monitor the teachers' progress, and provide them with support and supervision.

Since the success of the program depended on the support and cooperation it received from the school and community, the master trainers conducted motivational workshops with various stakeholders (e.g., school principals, parents, community members, and school governing bodies) to discuss the program. The discussions highlighted how culture and other issues pertinent to the community were taken into consideration in the development of the course.

The trained teachers implemented the life skills program in their schools. It was implemented over a number of weeks during the second and third quarters of the school term in 2001. Teachers were responsible for implementing the program with the learners selected for the study

\section{Research Methodology}

The study involved a multi-level design with master trainers, teachers, and learners included as participants. The following is a description of the research methodology for the evaluation of the intervention at the different levels.

\section{Teachers}

Twenty-six teachers completed a survey before and after training by the master trainers. The 26 teachers included 15 from the 11 intervention schools involved in the study. The survey data were used to assess changes in the teachers' knowledge about HIV and AIDS, attitudes toward teaching the subject matter, attitudes toward people with HIV and AIDS, confidence in their ability to teach the material, comfort with discussing HIV with students and others, and support of gender norms that foster protective attitudes and behavior among young men and women.

Teachers were also requested to complete a survey after they had finished teaching the course. The survey elicited information about actual course implementation, including the materials used, the content covered, and their experience in delivering the course.

\section{Learners}

The effectiveness of the program on the learners was measured in a pre-test, multiple post-test, control group design. Learners completed questionnaires at three time periods; baseline (T1), posttest or six months after the baseline (T2), and four months after the post-test (T3). A range of outcomes was assessed from the self-administered, written questionnaires. 


\section{Study Participants and Setting}

The study was carried out among grade nine, secondary school learners in the Pietermaritzburg region of KZN province. KZN has the largest school-going population (over 2.7 million learners) in South Africa. The two districts selected for the study had both rural and urban dwellers and a largely Zulu-speaking population. A number of teachers from the districts, according to the Department of Education's schedule for training, were among the first to be trained and thus their schools became part of the study's intervention group. The control schools were selected randomly from the remaining schools in the districts. Teachers from the control group were scheduled for training at a later date in accordance with the Department of Education's training schedule.

The learners were invited to participate on a voluntary basis and could withdraw at any stage if they wanted to. Written consent was obtained from parents and the Department of Education. There were no refusals from the parents or learners to participate. The Faculty of Medicine, Nelson R. Mandela Medical School, University of Natal granted ethical approval for the study.

\section{Sampling and Phases of Study}

Twenty-two schools participated in the study: 11 intervention schools and 11 control schools. Two grade nine classes at each of the selected schools were randomly selected to take part in the study. All the learners present in those classes were included in the study. Learners from both the control and intervention schools were requested to respond to a baseline questionnaire (T1). Six months later, the learners in the control schools completed the baseline questionnaire while the learners in the intervention schools received a questionnaire that included the questions from the baseline survey plus questions about the curriculum (T2). Four months after T2, learners from the control schools and the intervention schools completed the same questionnaire (T3). 


\section{Hgrizons}

\section{School Allocation and Learner Drop Out}

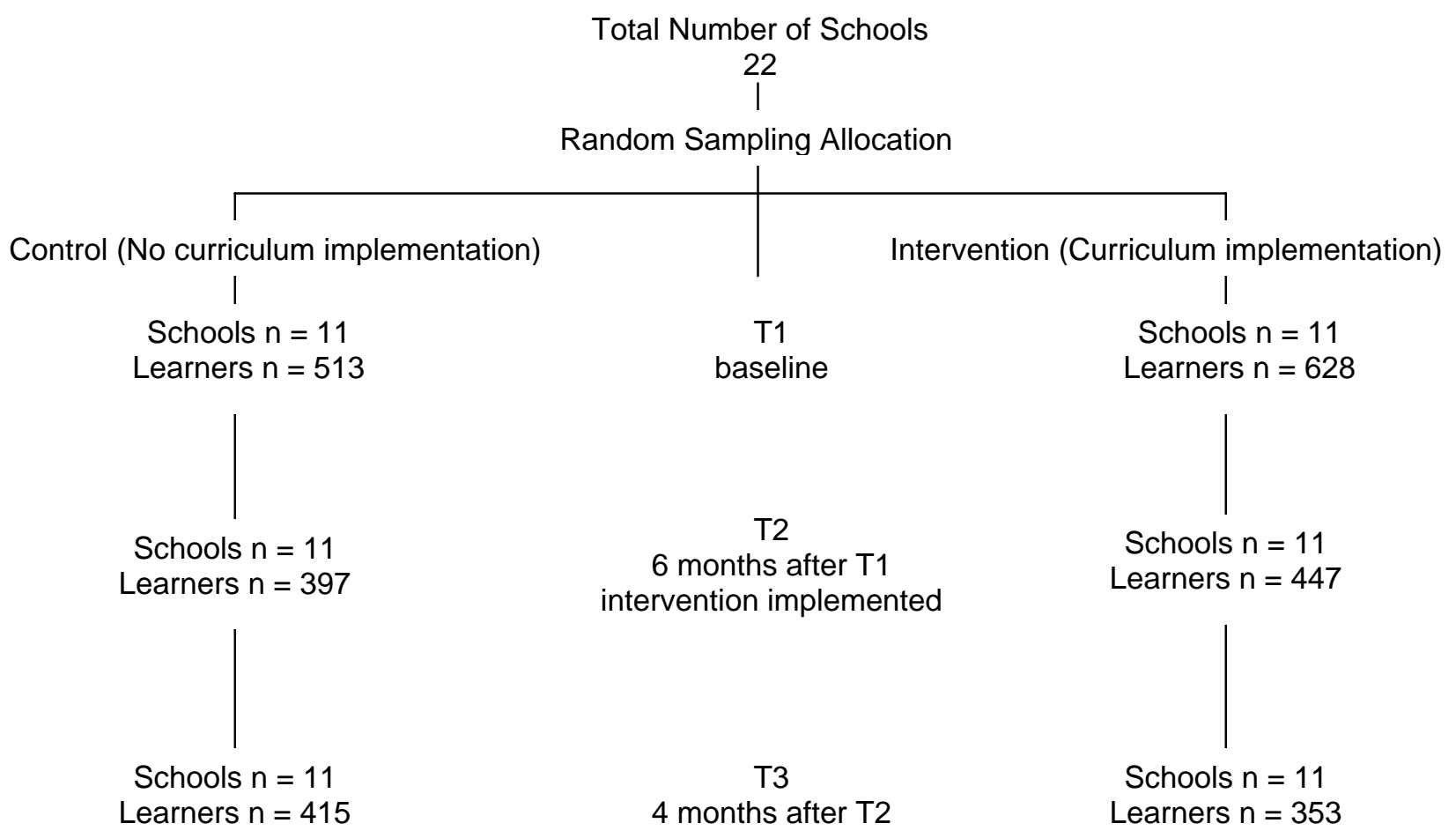

\section{Study I nstrument and Outcome Measures}

\section{Questionnaire}

A baseline, semi-structured questionnaire based on general cognitive frameworks, such as Ajzen's (1991) theory of planned behavior and Bandura's (1986) social cognitive theory, was used to collect data from learners. The instrument included questions about their demographic characteristics, HIV-related knowledge, attitudes toward condom use and people living with AIDS, perceptions about sexual behavior, communication about safer sex, social support, and ability to resist peer pressure. Learners also responded to questions about their general awareness and sources of information regarding sexually transmitted infections (STIs), including HIV, their perceived personal vulnerability to STIs, and their sexual behavior. The questionnaire was pretested among secondary school learners in the research area to ensure construct and face validity. The questionnaire was revised, pilot tested, and then finalized. Learners were able to answer the questionnaire in either English or Zulu. 


\section{Life Skills intervention}

The intervention was a 16-hour program, implemented during life orientation lessons at least once a week for two schools terms. The content covered a range of topics that was to be delivered through a combination of methodologies - didactic and interactive teaching, group work, and roleplay.

The content addressed the following issues:

HIV/AIDS facts

- Modes of transmission, immune system, HIV/AIDS progression

- Understanding my body

- Keeping my body safe and healthy

Life skills focusing on HIV/AIDS

- Self-esteem and self-awareness

- Relationships-family, peer group, community,

- Attitudes and values

- Sex and sexuality (abstinence, STIs, condom use)

- Rape and abuse

- Decision-making, conflict resolution, assertiveness

- Basic counseling skills, care and support

- Substance abuse

Teaching materials included:

- Body Wise

- Sexuality Education and the World of the Teenager

- Life Skills and HIV/AIDS Education

- Talking About Life-HIV/AIDS and Life Skills Training Manual

- Soul City Package

\section{Outcome measures}

Each of the constructs, that is knowledge, attitudes toward condom use and people living with HIV/AIDS, perceptions about sexual behavior, communication about safer sex, social support, and self-efficacy, were measured by a set of variables. To test if the variables were related to each other, factor analysis was used. The variables with a high loading $(>0.4)$ were grouped to form a factor and then interpreted and given meaning. This method of devising the factor by subjective interpretation is recommended with the "assumption that the researcher is in tune with the theoretical underpinnings of the data" (Breakwell, Hammond, and Fife-Shaw 1995). Factor analysis is therefore used when there is "a systematic interdependence among a set of variables and the researcher seeks to find out what creates the commonality of the variables to each other" (Reddy 2002). Factor analysis also reduces the number of variables to analyze, as the new variable 


\section{Hgrizons}

created is a scale comprised of the responses to several variables that are highly correlated to the new variable. These variables with a high correlation to the new variable are then subjected to a reliability test. A moderate to high alpha reading indicates that the individual variables share a commonality and are adequate to describe the concept captured by the scale.

\section{Knowledge about spread of HIV through non-sexual contact}

Learners were asked to respond to 18 statements related to the causes, transmission, and prevention of HIV. Responses included "true," "false," or "I don't know." Reliability analyses indicated one moderately reliable index (Cronbach's alpha $=0.66$ ). The index was knowledge about spread of HIV/AIDS through non-sexual contact (five items: the HIV virus can be contracted by sharing food with an infected person, by holding hands with an infected person, by hugging an infected person, by sleeping in the same room as an infected person, and by using the same toilet as an infected person).

\section{Attitudes:}

- Attitudes toward condom use: Learners' attitudes toward condom use and people with HIV/AIDS were measured. Attitudes toward condom use were measured using twelve items. After reducing the criteria factors to two, a scale of six items with moderate internal consistency (Cronbach's alpha $=0.65$ ) was structured. Areas covered included: condoms are embarrassing to use, condoms can harm the body, using a condom shows that you do not trust your partner, condoms take the fun out of sex, a woman loses a man's respect if she asks him to use a condom, and girls who carry condoms are not respected.

The second scale devised includes positive attitudes toward condoms (e.g., condoms work well to prevent the spread of HIV, condoms also prevent pregnancy, condoms are important to use every time you have sex) and had a moderate internal consistency (Cronbach's alpha $=0.65$ ).

- Attitudes toward people living with HIV/AIDS: Nine items assessed the attitudes of learners toward people living with HIV/AIDS. Six of these items were combined into a scale of adequate internal consistency (Cronbach's alpha $=0.74$ ). These items included whether a student with HIV, the virus that causes AIDS, should attend school and whether a teacher with the virus should be allowed to continue teaching at school. The items also examined attitudes about being in the same classroom as a HIV-positive learner, hugging a friend with HIV/AIDS, caring for a relative with HIV/AIDS in your household, and buying food from an HIV-positive shopkeeper. All of these items reflect learners' attitudes about having close social contact with a person who is HIV-positive or has AIDS.

Perceptions of social support: Eight items were used to determine the learners' perceptions of support from significant people like family, friends, and teachers. Six of these items (teachers at this school care about the students, there is a teacher that I can talk to if I have a problem, my mother cares about me a lot, my father cares about me a lot, my family pays attention to me a lot, 
when I do well my family praises me) were combined into a scale with an adequate internal consistency (Cronbach's alpha $=0.71)$.

Confidence to assert oneself: Seven statements were posed to learners that probed their perceptions of their confidence to resist pressure with regard to drinking alcohol, using drugs, and refusing sex; to ask a partner to use a condom; to use a condom correctly; and to know where to take an HIV test. These items were combined into a scale with an adequate internal consistency (Cronbach's alpha $=0.77)$.

Perception of and beliefs about sexual behavior: Several statements about beliefs related to sexual behavior were subjected to factor analysis. Six of these items (men need to have more than one sexual partner, often at the same time; my friends encourage me to have sex; it is okay for a boyfriend to force his girlfriend to have sex; I must have sex to keep my boyfriend or girlfriend; it is alright for a boy to demand sex from a girlfriend; and it is alright for a girl to demand sex from a boyfriend) had loadings higher than 0.4 and were reflective of normative beliefs about sexual behavior. A scale of these items had a moderate internal consistency (Cronbach's alpha $=0.75$ ).

Communication about HIV/AIDS and safer sex: Five statements related to the appropriateness of a male or female partner to bring up the subject of HIV/AIDS and safer sex were combined into a scale with high internal consistency (Cronbach's alpha $=0.83$ ). The items were: it is okay for a girl to bring up the subject of HIV/AIDS with her boyfriend, a boy should be able to ask whether his partners have other sexual partners, a girl should be able to ask whether her partners have other sexual partners, a boy should be able to talk to his partner about safer sex, and a girl should be able to talk to her partner about safer sex.

Sexual behaviors: Learners were asked several questions to determine whether they had ever had sex, were sexually active during the recall period, their age of sexual debut, the number of partners they had in the recall period, and their condom-using behavior.

Sexual behavior intentions: Learners were asked about their intention to use a condom when they next have sex, and whether in the next three months they intend to not have sex, to have sex with a condom, or have sex without a condom.

\section{Demographic Profile of Learners}

Table 1 illustrates the demographic profile of the respondents at baseline. The mean age of the learners was 15.6 years old (youngest respondent was 12 years old and the eldest was 21 years old). The majority of respondents were Zulu-speaking ( 88 percent) and there was an almost equal distribution of male ( 48 percent) and female ( 52 percent) learners. No statistically significant differences in demographic data between the intervention and control groups were found at baseline. 
Table 1 Sociodemographic profile of respondents at baseline

\begin{tabular}{|c|c|c|c|c|c|c|}
\hline \multirow[t]{2}{*}{ Variables } & \multicolumn{2}{|c|}{ Control group } & \multicolumn{4}{|c|}{ Intervention group } \\
\hline & $\begin{array}{l}\text { Male } \\
\text { n (\%) }\end{array}$ & $\begin{array}{c}\text { Female } \\
\text { n (\%) }\end{array}$ & $\begin{array}{l}\text { Total } \\
\text { n (\%) }\end{array}$ & $\begin{array}{l}\text { Male } \\
\text { n (\%) }\end{array}$ & $\begin{array}{c}\text { Female } \\
\text { n (\%) }\end{array}$ & $\begin{array}{l}\text { Total } \\
\text { n (\%) }\end{array}$ \\
\hline \multicolumn{7}{|l|}{ Age (years) } \\
\hline $12-15$ & $104(20)$ & $150(29)$ & $254(49)$ & $131(21)$ & $159(25)$ & $290(46)$ \\
\hline $16-18$ & $111(22)$ & $106(21)$ & $217(42)$ & $138(22)$ & $144(23)$ & $282(45)$ \\
\hline $19-21$ & $14(3)$ & $5(1)$ & $19(4)$ & $21(3)$ & $3(1)$ & $24(4)$ \\
\hline Missing & & & $23(4)$ & & & $32(5)$ \\
\hline Total & $229(45)$ & $261(51)$ & $513(100)$ & $290(46)$ & 306 (49) & $628(100)$ \\
\hline \multicolumn{7}{|l|}{$\begin{array}{l}\text { Home } \\
\text { language }\end{array}$} \\
\hline English & $27(5)$ & $28(5)$ & $55(11)$ & $30(5)$ & $37(6)$ & $67(11)$ \\
\hline Zulu & $205(40)$ & $234(46)$ & $439(86)$ & $262(42)$ & $271(43)$ & $533(85)$ \\
\hline Other & 1 & 2 & $3(1)$ & $4(1)$ & 1 & $5(1)$ \\
\hline Missing & & & $16(3)$ & & & $23(4)$ \\
\hline Total & $233(45)$ & $264(51)$ & $513(100)$ & 296 (47) & 309 (49) & $628(100)$ \\
\hline \multicolumn{7}{|l|}{ Religion } \\
\hline Christian & $173(34)$ & $222(43)$ & $395(77)$ & $250(40)$ & $281(45)$ & $531(84)$ \\
\hline Other & $40(8)$ & $27(5)$ & $67(13)$ & $31(5)$ & $19(3)$ & $50(8)$ \\
\hline Missing & & & $51(10)$ & & & $47(8)$ \\
\hline Total & $213(42)$ & 249 (48) & $513(100)$ & $281(45)$ & $300(48)$ & $628(100)$ \\
\hline
\end{tabular}

Note: Totals do not include missing data. 


\section{Results}

\section{Sexual Activity}

\section{The program did not increase sexual activity.}

Many adults were concerned that school programs that give learners information about safe sexual behavior may encourage young people to become sexually active. To test for this possibility, the researchers asked the students whether they had had sex during the last six months at baseline (just before the program started) and six month later when the course concluded. By comparing the change in this behavior between the control group that did not participate in the program and the intervention group that did participate, it is possible to see whether a greater proportion of the intervention group was sexually active than would be expected.

Study data indicates that less than a third of the students in both groups had had sex in the six months before the course (Figure 1). That is, 111 of the control group of 363 learners and 128 of the intervention group of 424 learners at baseline. After the course more students in both the control and intervention groups had had sexual intercourse as one might expect as youth get older, but those who participated in the program were slightly less likely to have done so than those in the control group (36 percent vs. 37 percent). Although the difference between the two groups of learners is small, these findings indicate that participation in the course did not lead to an increase in sexual activity. Although fewer females than males reported sexual activity at both points in time, the trend over time was similar for males and females.

\section{Figure 1 Learners' reported sexual activity at T1 and T2}

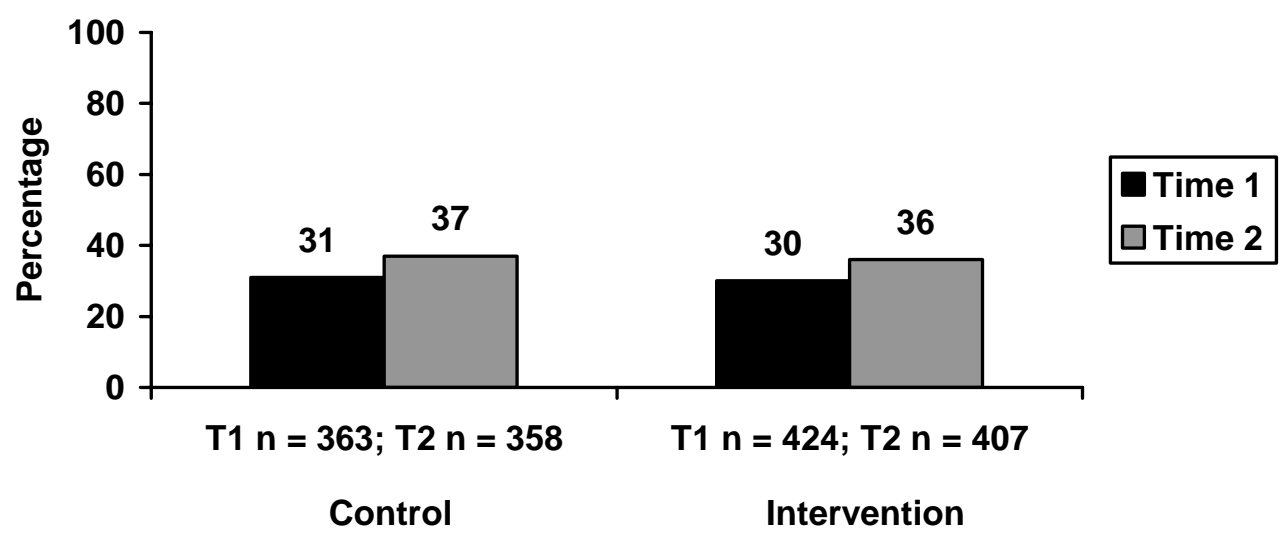




\section{Youth go through periods of abstinence despite having initiated sexual activity.}

Although more males than females reported ever having been sexually active, comparable proportions of male and female youth reported having sex in the six-month recall period. For example, at T2, 64 percent and 58 percent of males in the control and intervention groups, respectively, reported ever having had sex, while the figures for females were much lower-29 percent and 30 percent, respectively. However, when those who were sexually experienced were asked about having sex during the recall period, 61 percent and 55 percent of males and 62 percent and 55 percent of females in the control and intervention groups, respectively, had done so. This highlights that youth go through periods of abstinence despite having initiated sexual activity and that male and female students are almost as equally likely to do so.

\section{Learners did not increase their intention to have sex.}

Learners were asked whether they planned to have sex in the next three months. At baseline more than two-thirds of students in both the control and intervention groups did not intend to have sexual intercourse in the next three months, and a similar proportion maintained this intention to remain abstinent at the end of the course and then four months later. Figure 2 illustrates the data for the intervention group.

\section{Figure 2 Intervention group's learners' report of intended sexual activity in the next three months}

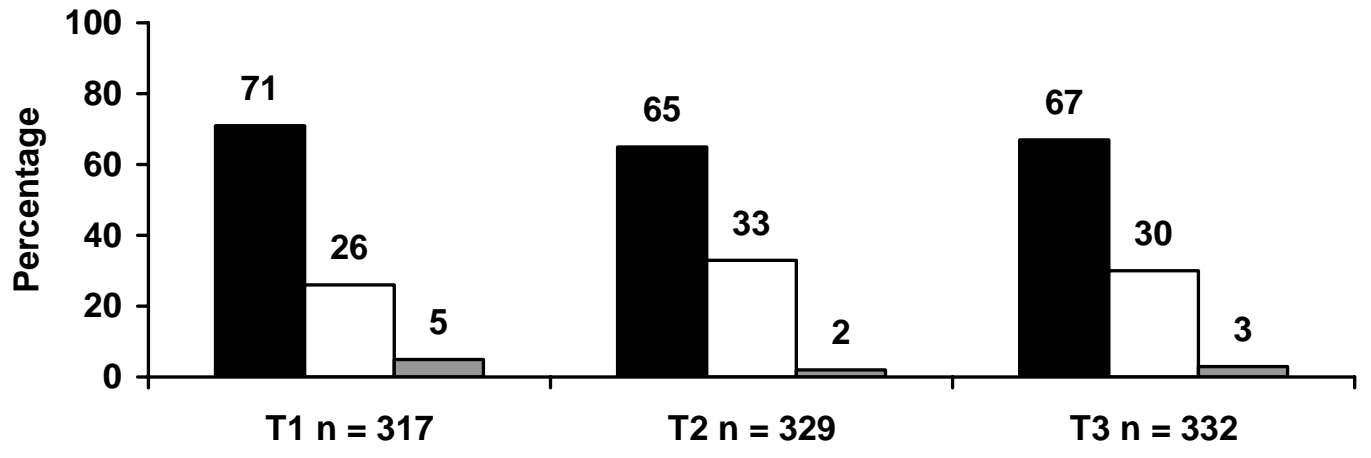

Not have sex $\square$ Have sex wl condom $\square$ Have sex wlo condom

Among those students who did intend to have sexual intercourse, a significantly greater proportion of learners in the intervention group intended to use a condom at T2 than did those in the control group $(\mathrm{p}<.009)$ (Figure 3$)$. There was no statistically significant difference between male and female learners on these measures. 
Figure 3 Percentage of youth who plan to have sex with a condom in next three months

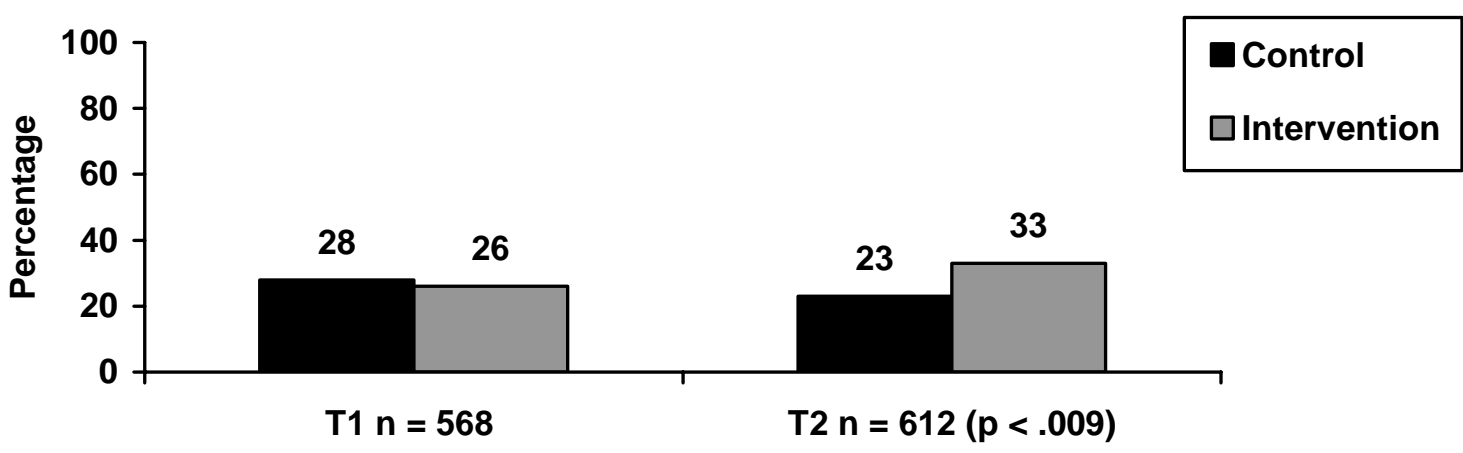

\section{Approval of teenage abstinence increased within the intervention group, particularly among males.}

The study measured students' attitudes about abstinence in two ways. First, they were asked whether it was acceptable for teenagers not to have sex. At baseline, 54 percent of the males in the experimental group agreed with the statement; at T2, this figure increased to 81 percent $(\mathrm{p}<.001)$. At $\mathrm{T} 3$ the proportion decreased slightly to 73 percent, but was still significantly greater compared to T1 $(\mathrm{p}<.001)$. No similar trend was detected among males in the control group or among females in either group.

Students were also asked if they believed that it was a good idea not to have sex while a teenager. As shown in Figure 4, 61 percent of intervention males and 76 percent of intervention females supported abstinence among teenagers at baseline. For both groups there was a statistically significant increase in the proportion that agreed with the statement at T2 (males: $\mathrm{p}<.001$; females: $\mathrm{p}<.05$ ), and this was maintained for both groups at T3. In contrast, support for abstinence among the control group was less at T2 and T3 compared to T1.

\section{Learners cited "not ready" and “to protect health" as reasons to abstain from sex.}

At T2, learners were asked a series of questions focused on abstinence. One such question asked learners to cite reasons why abstinence was a good idea. Because these questions were only asked during the second round of data collection, it is difficult to draw conclusions about programmatic impact on these beliefs. However, a greater proportion of both males and females in the intervention group cited not being ready and protecting their health as reasons why they supported abstinence compared to the control group. 
Figure 4 Percentage of students who believe teenagers should be abstinent

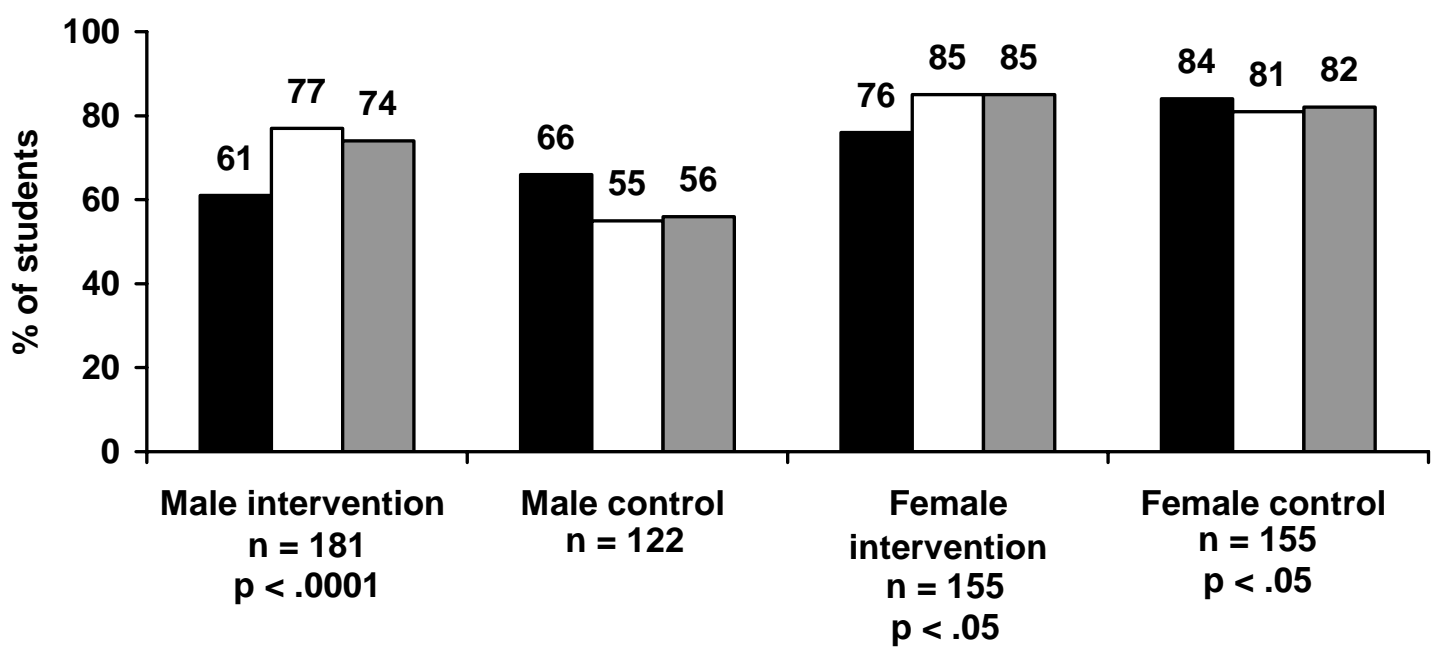

- Time $1 \quad \square$ Time $2 \quad \square$ Time 3

For example, 56 percent of male students in the control group compared to 73 percent of male students in the intervention group believed that abstinence was a good idea if you are not ready to have sex, and this difference was statistically significant $(\mathrm{p}<.002)$. Similarly, a significantly greater proportion of males in the intervention group believed that abstinence was a good idea because it protected health compared to the control group ( 83 percent vs. 71 percent; $p<.013$ ). Although intervention females were more likely to cite both reasons than control females, the differences were not statistically significant.

\section{In both the control and intervention groups, learners' understanding that abstinence protects from HIV increased over time.}

Students were presented with the following statement on the T1 and T2 surveys: "People can protect themselves from getting the HIV virus by not having sexual intercourse." At baseline, about two-thirds of students in the control (66 percent) and intervention (63 percent) groups responded affirmatively. These proportions increased at T2 to 69 percent and 73 percent, respectively, and remained relatively stable at $\mathrm{T} 3$ ( 72 percent and 73 percent, respectively). The changes in these proportions within each round of data collection were not statistically significant. This indicates that messages outside of those provided in the curriculum were influencing students' knowledge about abstinence and HIV transmission. 


\section{Young men reduced their number of sex partners slightly.}

At baseline, the vast majority of sexually experienced students reported no partner or just one partner in the previous six months, and this remained stable at T2 and T3. Researchers then examined the change in the number of partners over time. For example, among male students reporting more than one partner at $\mathrm{T} 1$, a greater proportion in the intervention group said they were monogamous at T2 compared to males in the control group (27 percent vs. 21 percent). Similarly, the proportion of intervention males who reported being monogamous at T1 but said they had more than one partner at T2 was less than the proportion of control males who reported this ( 7 percent vs. 25 percent). Although these differences are not statistically significant, they suggest a trend among intervention males toward maintaining or switching to monogamy. Few females had multiple partners in either the intervention or control group.

\section{Knowledge}

\section{Program did a good job of providing needed information}

The course was most successful in increasing the amount of correct information that learners had about HIV/AIDS. Achieving an increase in knowledge as compared to improving attitudes, skills, and behavior may reflect the fact that while most of the teachers covered the informational aspects of the curriculum, some did not cover the skills activities (refer to page 30 for more information). As teachers become more comfortable with the materials, it is likely that they will begin teaching the whole curriculum. In the meantime the evaluation indicates that the learners did well in terms of knowledge gains about HIV/AIDS.

Another challenge to life skills courses is presenting basic HIV prevention and care information that engages all learners. The study indicated that the learners had different levels of knowledge prior to the course, making the job more difficult. Many were very knowledgeable, but others had limited information. Baseline data from the study revealed, for example, that about 80 percent of students knew that a person could not transmit HIV by shaking hands. This indicates that most were well informed about this aspect of transmission, but one-fifth believed that HIV could be transmitted through casual contact.

Figure 5 shows the mean number of questions the learners correctly answered out of a total of 15 questions on HIV knowledge. At baseline, both control and intervention learners had a mean score of 13 correct answers. As a result of participating in the course, the mean number of correct answers increased for intervention learners while the mean number remained largely unchanged for the control learners. 
Figure 5 Mean number of correct answers for learners on knowledge section about HIVIAIDS

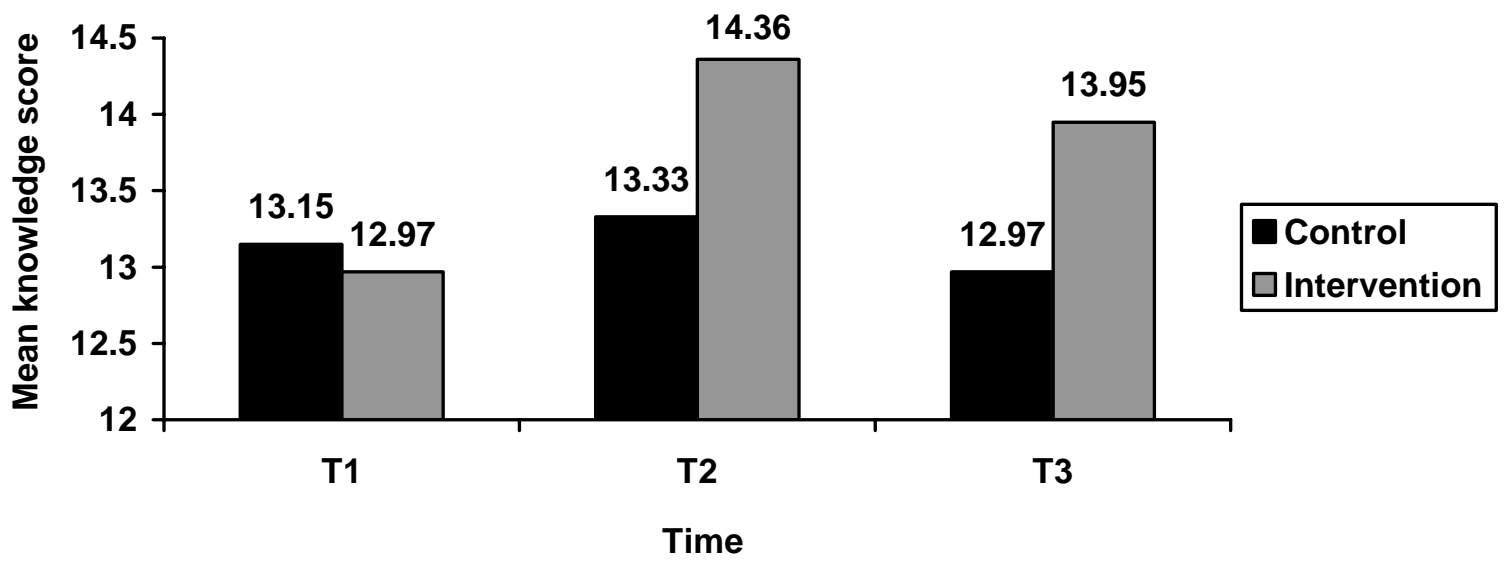

Table 2 shows the questions that the students were asked and the level of improvement from TI to T2. For example, learners improved on questions about whether it is possible to get HIV from sleeping in the same room as an infected person, using the same toilet as an infected person, hugging an infected person, and sharing food with an infected person. There was also a significant increase in the proportion that correctly answered questions about contraceptive pills and HIV prevention. While many of the students knew about HIV prevention and methods of transmission, there were still some students that had limited HIV prevention knowledge. These results should help educators identify student needs.

\section{Relationships}

\section{When asked about relationship issues, many learners marked "unsure."}

Further examination of the data indicates that for several questions that focused on gender and relationships, many learners answered that they were "unsure" about the statements. For example, when asked whether they agreed with the statement "if a girl refuses to have sex she would lose her boyfriend," most learners in the intervention group answered that they were unsure whether this was true at all three time periods. Figure 6 displays the shift from "disagree" and "agree" to "unsure," with the greatest change occurring immediately after the course (T2). These topics may present special opportunities for class discussion because so many students had ambivalent opinions. 
Table 2 Percentage of learners answering knowledge questions correctly at T1 and T2

\begin{tabular}{|c|c|c|}
\hline Question & $\begin{array}{c}\% \\
\text { correct } \\
\text { at T1 }\end{array}$ & $\begin{array}{c}\% \\
\text { correct } \\
\text { at T2 }\end{array}$ \\
\hline A person can get HIV by having sexual intercourse without protection & 89 & 92 \\
\hline A person can get HIV by sleeping in the same room as an HIV+ person & 69 & $88^{*}$ \\
\hline $\begin{array}{l}\text { A person can get HIV by coming into contact with the blood of an HIV+ } \\
\text { person }\end{array}$ & 83 & $91^{\star *}$ \\
\hline A person can get HIV by using the same toilet as an HIV+ person & 64 & $77^{*}$ \\
\hline A person can get HIV by sharing needles with an HIV+ person & 90 & 92 \\
\hline A person can get HIV by holding hands with an HIV+ person & 81 & $91^{*}$ \\
\hline A person who looks healthy can be infected with the HIV virus & 57 & $62^{\star \star *}$ \\
\hline $\begin{array}{l}\text { People can protect themselves from HIV by using a condom correctly every } \\
\text { time they have sex }\end{array}$ & 86 & 82 \\
\hline $\begin{array}{l}\text { People can protect themselves from HIV by having one uninfected sex } \\
\text { partner who also has no other partners }\end{array}$ & 67 & $80^{*}$ \\
\hline People can protect themselves from HIV by not having sexual intercourse & 63 & $73^{\star \star \star}$ \\
\hline $\begin{array}{l}\text { A person can get infected with HIV by getting injections with a clean, sterile } \\
\text { needle }\end{array}$ & 76 & 76 \\
\hline HIV can be passed from a pregnant mother to her unborn child & 87 & 84 \\
\hline $\begin{array}{l}\text { A person can protect him/herself from HIV by taking family planning pills or } \\
\text { injections }\end{array}$ & 42 & $55^{\star \star \star}$ \\
\hline A person can get HIV by sharing food with an HIV+ person & 68 & $76^{\star \star \star}$ \\
\hline HIVIAIDS is caused by condoms & 85 & 82 \\
\hline HIVIAIDS is caused by girls & 65 & 68 \\
\hline HIVIAIDS is caused by witchcraft & 71 & $90^{*}$ \\
\hline You can get HIVIAIDS by hugging an infected person & 85 & $95^{\star}$ \\
\hline
\end{tabular}

${ }^{*} \mathrm{p}<.001,{ }^{* \star} \mathrm{p}<.01,{ }^{* \star *} \mathrm{p}<.05$ 
Figure 6 Learners' beliefs about the repercussions of girls not engaging in sexual activity with their boyfriend

If a girl refuses to have sex she will lose her boyfriend.

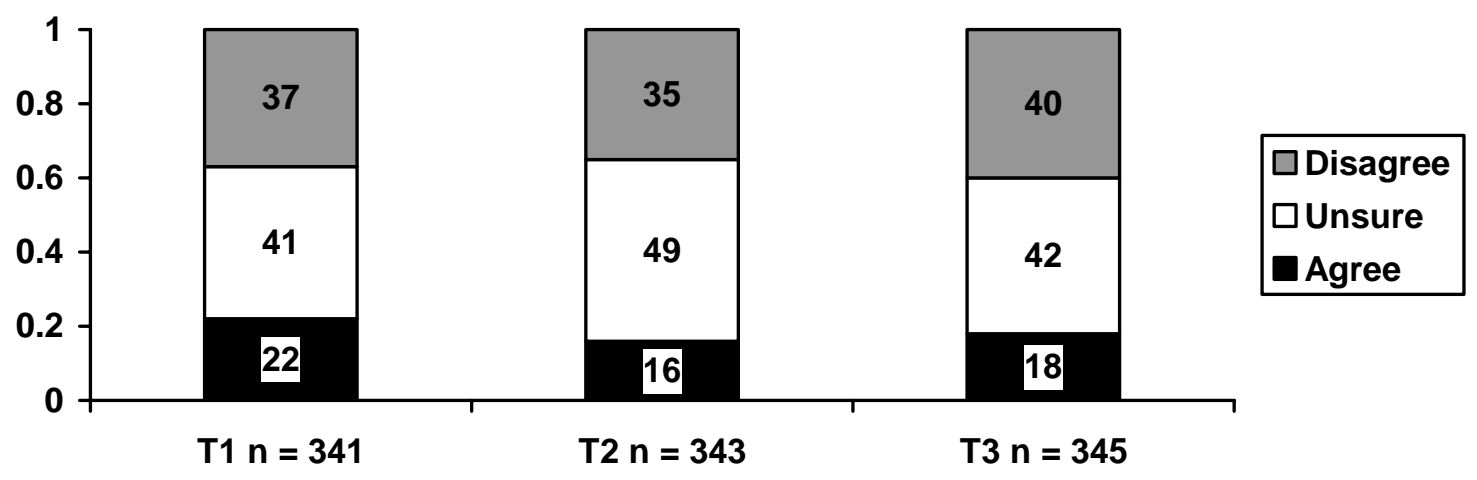

\section{Youth already had some positive attitudes and behaviors.}

This evaluation revealed several strengths among the learners that the Life Skills Programme can reinforce and build on. For example, students were asked whether they agreed with the statement "it is OK for a boyfriend to force his girlfriend to have sex." Despite high levels of partner violence in South Africa, it was encouraging to find that at each data collection point the vast majority of males and females in both the intervention and control groups did not support sexual coercion by boyfriends. As shown in Figure 7, more than 80 percent of learners in the control and intervention groups did not agree with the statement at baseline and the percentage for both groups increased at T3. The levels were also similar for males and females.

Other positive indicators detected at baseline were that less than five percent of the learners felt that it was all right for a boy to demand sex from a girl and about 85 percent of sexually experienced learners in both control and experimental groups reported using a condom in the last six months.

\section{Attitude Toward People Living with HI V/ AI DS}

\section{There were some positive trends among learners in both the control and intervention groups.}

When comparing the responses of the control and intervention groups, it is clear that, on some measures, the learners in both groups made improvements. For example, young people increased their tolerance of people living with HIV/AIDS, as evidenced by a significant increase among learners in the intervention $(\mathrm{p}<.0001)$ and control groups $(\mathrm{p}<.0001)$ who reported that they 
Figure 7 Learners' attitudes toward forced sex

Learners who disagree that it is OK to force a girl to have sex

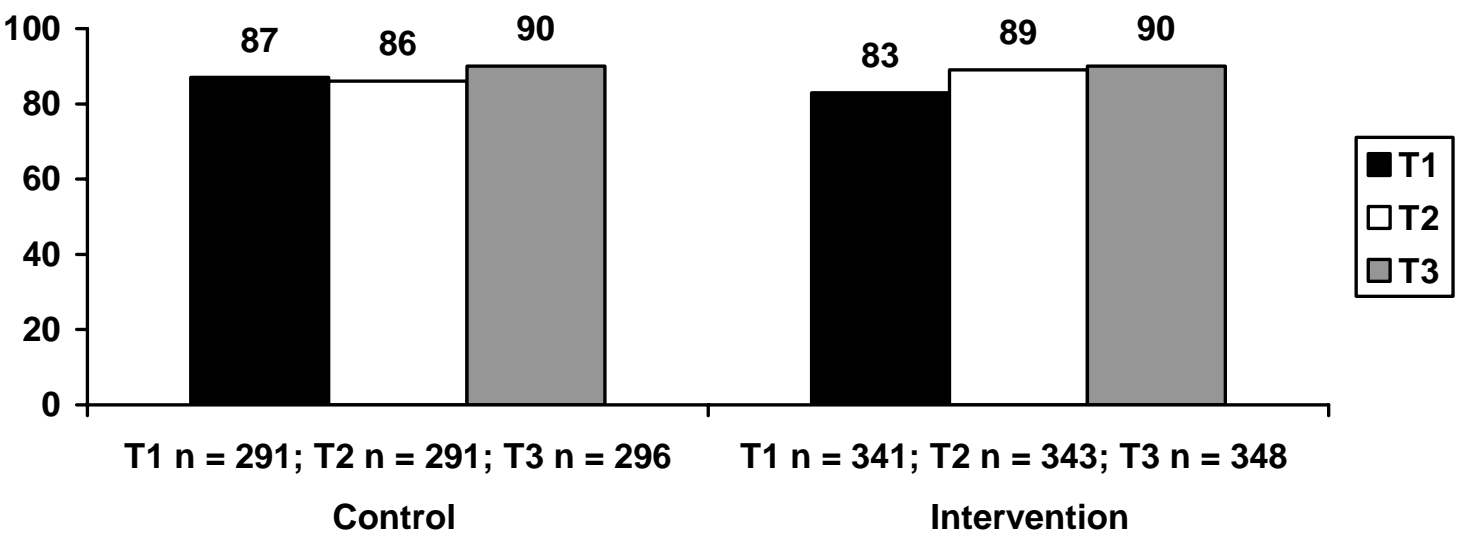

would not mind having an HIV-positive learner in the classroom (Figure 8). Comparing males in the two groups, there was a significant increase in both groups, but the increase was greater in the intervention group $(p<.006)$ compared to the control group $(p<.014)$. The same positive trend was observed for female respondents, but the level of change over time was the same for both intervention and control groups $(\mathrm{p}<.0001)$.

Similarly, there were statistically significant changes for males and females in each group when comparing their responses regarding tolerance of HIV-positive teachers across the three rounds of data collection (Figure 9). However, the change was greater in the intervention group (males: $\mathrm{p}<$ .0001 ; females: $\mathrm{p}<.0001$ ) compared to the control group (males: $\mathrm{p}<.041$; females: $\mathrm{p}<.030$ ).

These findings suggest that there are other sources of information and communication about HIV that positively affected all of the young people who were surveyed. In fact, the researchers and educators reported that while the course was being taught, other interventions were ongoing, including media programs from Soul City and LoveLife, community AIDS awareness efforts from clinics and health workers, and national activities focused on World AIDS day (December 1st).

\section{Male and Female Learners had Different Needs and Outcomes}

The data indicates that males and females had different needs going into the course and that the course impacted them differently. For example, twice as many males as females were sexually experienced at baseline, indicating a higher risk of HIV infection for young men. However, a greater proportion of sexually experienced females reported more than one partner within the recall period than males ( 90 percent vs. 75 percent). 
Figure 8 Learners' attitudes toward an HIV-positive classmate

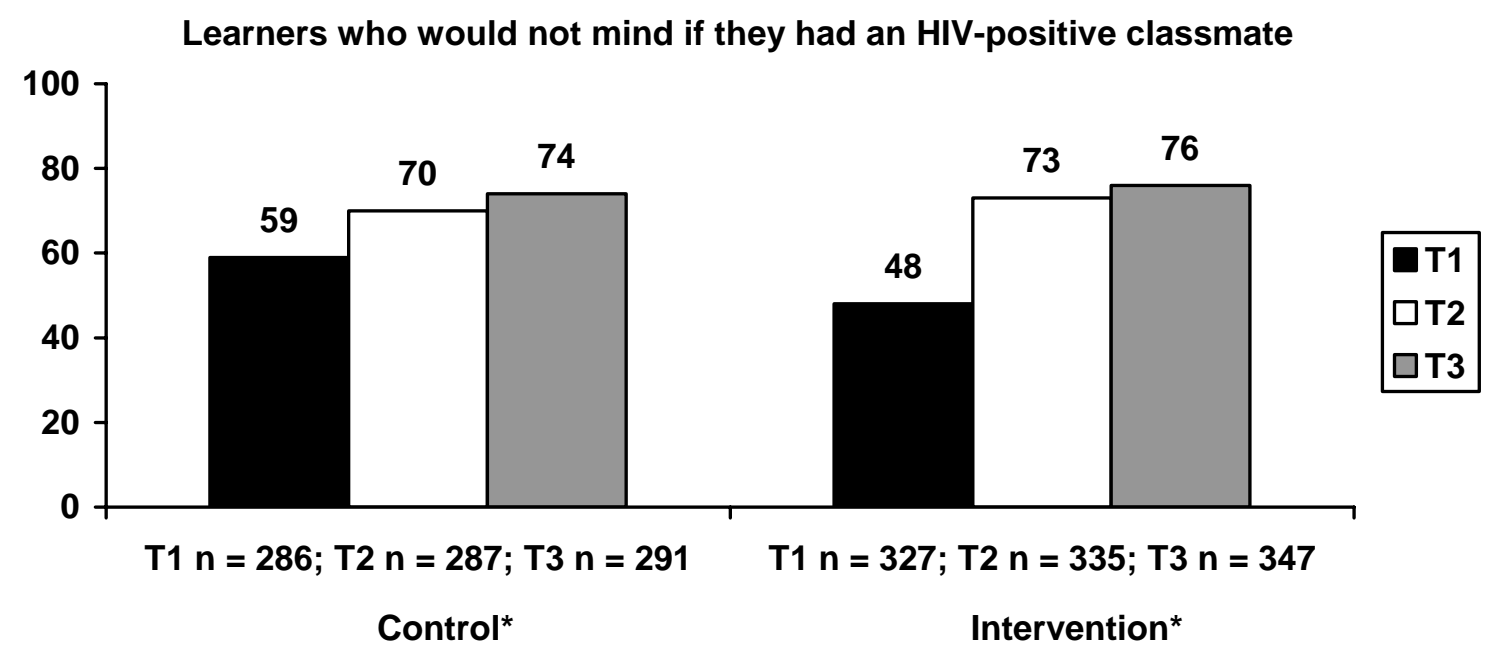

Figure 9 Learners' attitudes toward an HIV-positive teacher

Students who believe that a teacher who is HIV-positive should continue teaching

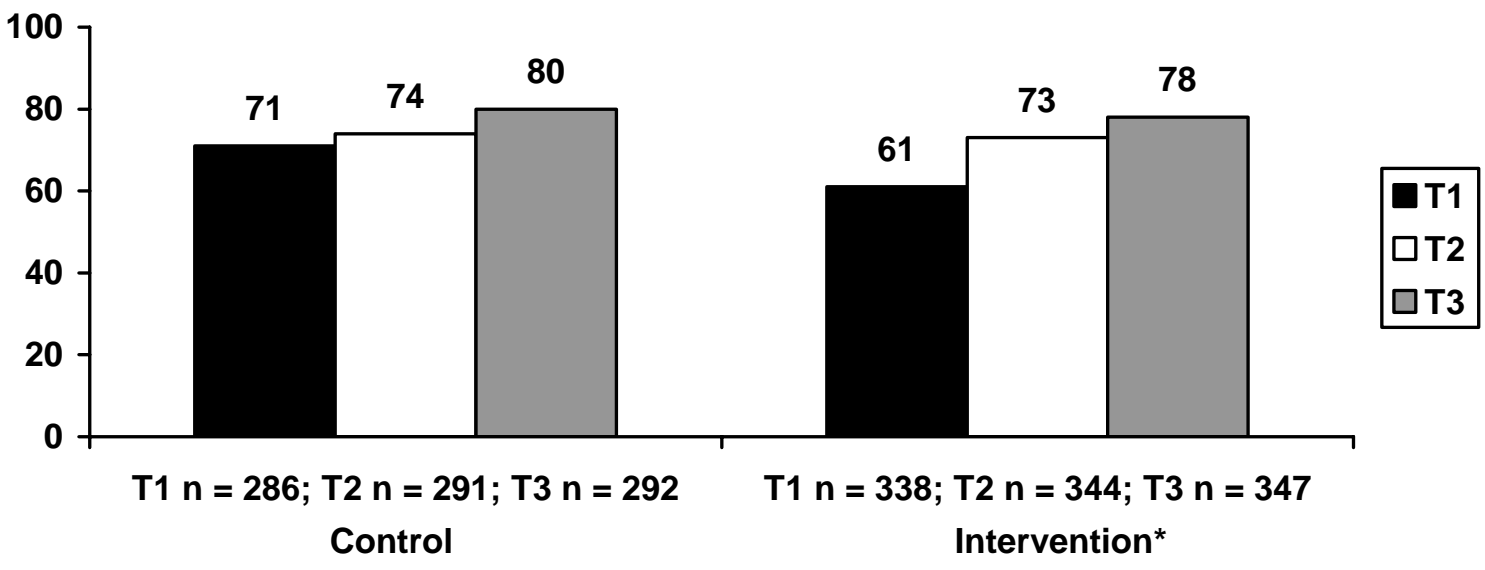

Males and females also had different attitudes and degrees of change in attitudes. At baseline, more females than males thought that it was OK for teens not to have sex ( 76 percent vs. 61 percent). Because the proportion of males was lower at baseline, there was more room for improvement. After participating in the intervention, the proportion of males who felt it was OK not to have sex increased significantly from 61 percent to 76 percent $(p=0.008)$. While the proportion of females who agreed with the statement also rose, the degree of change was not as great (76 percent to 86 percent; NS). 


\section{Learners' Perceptions of the Program}

Learners were asked several questions to determine what their impressions were about the teacherimplemented program. Their responses reflect a general liking of the program and allude to its beneficial qualities.

\section{Program was Educational and Useful}

Most of the learners agreed that the program was interesting ( 77 percent), informative ( 83 percent), educational ( 86 percent), and useful ( 86 percent). Learners also said that they liked the course because it increased their knowledge about HIV/AIDS (78 percent), life skills ( 88 percent), and how to protect themselves from getting infected with HIV ( 80 percent). In addition, learners were happy to participate in class discussions ( 81 percent).

Most said that the teacher presented the lessons in a way that they understood ( 83 percent), the teacher used methods to encourage learner participation ( 82 percent), the teacher was honest in the way he/she talked about HIV/AIDS ( 83 percent) and its prevention ( 82 percent), and the teacher answered the learners' questions clearly ( 82 percent).

\section{I ncreased Confidence and Communication about HI V/ AI DS}

One goal of the Life Skills Programme was to increase the learners' confidence and communication about HIV/AIDS prevention and care with the important people in their lives. Progress toward this goal was measured in part by asking the learners whether the course had increased their confidence to communicate. When surveyed just after the course ended (T2), the majority of male and female learners reported greater confidence in speaking to their siblings, friends, parents, and partners (Figure 10).

The learners were also asked if they had discussed what they had learned about HIV/AIDS with various people in their lives (Figure 11). In many cases, a high proportions of learners reported communicating about HIV with members of their social networks. The most frequently mentioned group was school friends. It is important to note that more males than females ( 29 percent vs. 8 percent) reported that they had not talked to anyone about what they had learned. Special efforts will be needed to facilitate discussion about HIV/AIDS among young men. Respondents also noted increased confidence to talk about the HIV/AIDS with different groups. For example, more than half (56 percent) of learners said they had increased confidence to talk with their parents about HIV/AIDS. 
Figure 10 Confidence to talk about sexual issues with my...

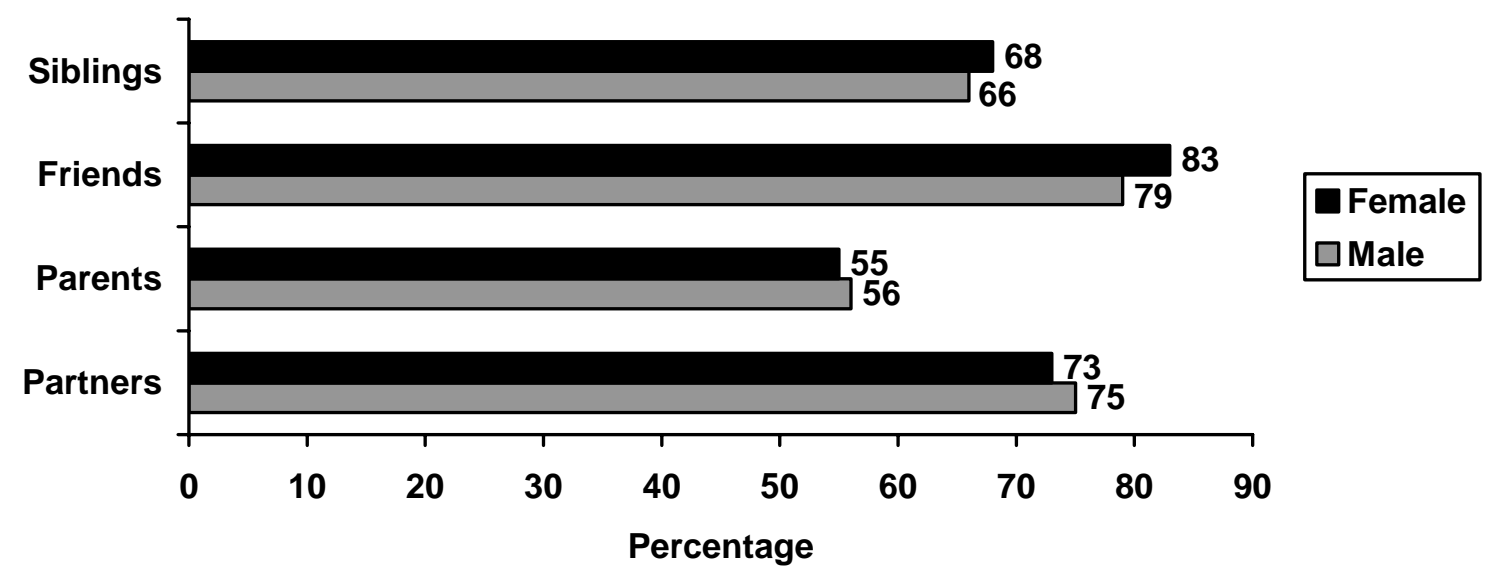

Figure 11 Learners discussed Life Skills Programme with...

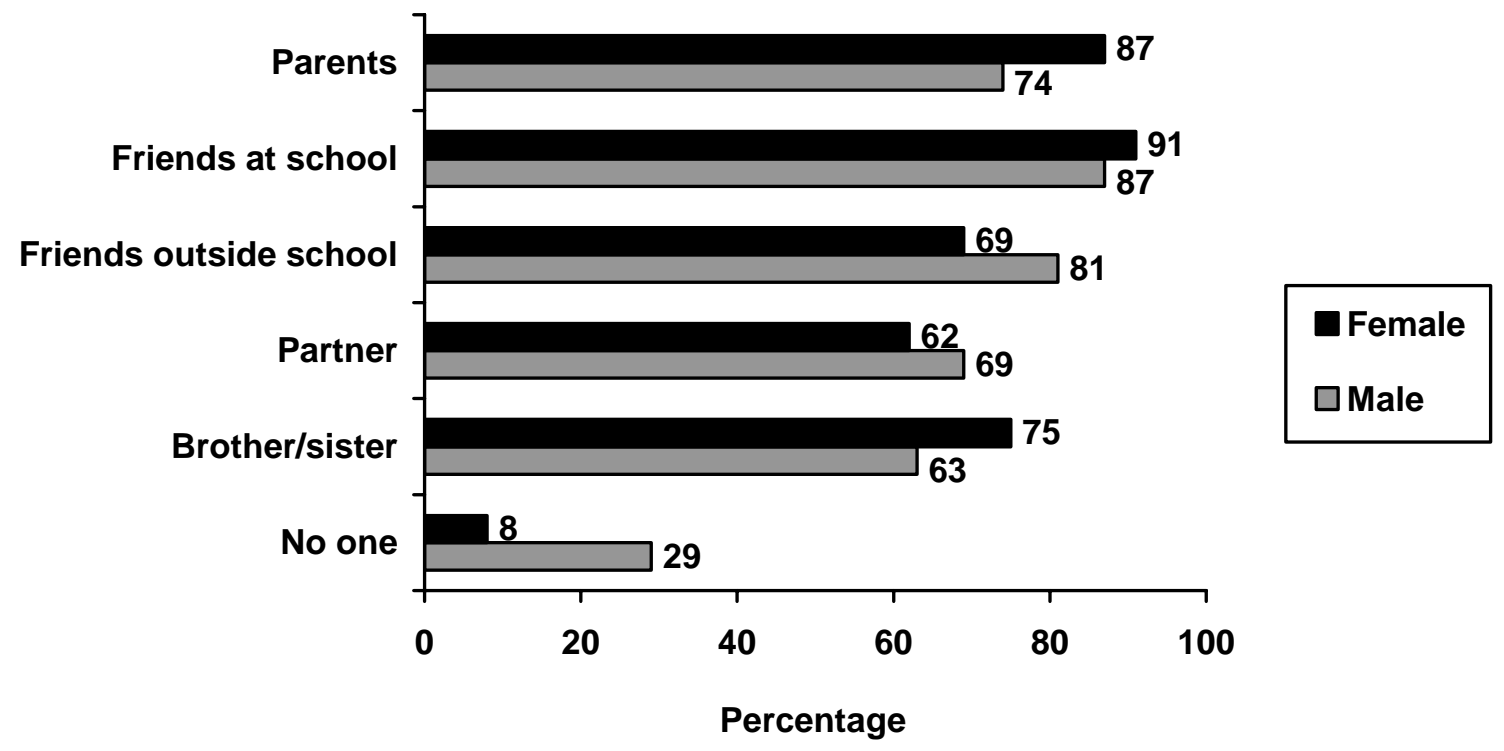

\section{Minority of Learners had Mixed Reactions}

The data provided information about how the Life Skills Programme could be improved in the future. For example, more than a fourth of learners found the lessons to be frightening and 25 percent were unsure if the lessons were offensive. While 17 percent and 12 percent of the learners agreed with the statements that they disliked the lessons because HIV/AIDS was not their problem and that school was not the place to discuss HIV/AIDS, 15 percent of the learners responded that 
they were unsure about these statements. Although these are the opinions of a small group of the students, the needs of these students must also be addressed.

With regard to the teachers' performance, some students expressed doubts about the teachers' ability to present the class material. More than a fifth of students were unsure whether the teacher accepted learners' opinions without judgment, were unsure about the their satisfaction with teachers' answers to most questions, and were unsure about the teacher's comfort using sensitive words for body parts and sexuality. A similar proportion of learners were not confident in and unsure of their abilities to resist pressure from friends to engage in sexual activity: 22 percent felt they were not confident and another 22 percent were unsure about their ability to resist pressure.

Learners expressed interest in learning more about the topics included in the Life Skills Programme. At least 60 percent of learners indicated that they need more skills to resist pressure from friends, to talk to their partners about sex, and to prevent themselves from becoming infected with HIV/AIDS. A similar percentage indicated that they needed more practice in negotiating and using condoms. 


\section{Teachers' Experiences and Suggestions}

\section{Teacher Selection and Characteristics}

When requesting teachers to attend the life skills HIV/AIDS training course, the Department of Education included a list of criteria that needed to be considered by schools when nominating teachers. According to the list, the nominated teachers needed to be:

- committed.

- comfortable with the topic of sexuality and HIV/AIDS education.

- able to respect confidentiality.

- able to create a favorable climate for sensitive discussions.

- empathetic and objective.

- able to organize effectively.

- able to coordinate resources in the community.

Each of the eleven intervention schools had one teacher trained (6 females and 5 males) to present the program to learners. Their ages ranged from 25 to 50 years old. Ten of the teachers named Zulu as their home language and the other one reported English. Nine of the teachers had one to four years of teaching life skills with one indicating 20 years and the other no previous experience. When asked about the schools' responsibility to teach life skills, almost all of the teachers (96 percent) responded positively on the pre-test survey.

\section{Training Components and Effectiveness}

\section{Master training (train the teachers)}

The master training was coordinated by the Psychological and Guidance Special Education Services (PGSES). It consisted of a five-day workshop of which two and a half days were dedicated to HIV and AIDS prevention. The participants were staff of PGSES who after receiving the master training (for both primary and secondary schools) were expected to be equipped with skills to train the teacher in their respective regions. Many of the participants had attended the previous master training course in 1997.

The current course aimed to reinforce and consolidate the master trainers' knowledge and skills in sexuality education. Topics addressed during the course included sexuality; theory of behavior change; transmission and treatment of HIV/AIDS; life skills; peer education; and management, monitoring, and evaluation of the implementation of the course with learners. These topics aimed to complement the participants' existing knowledge. PGSES staff and external specialists facilitated the course presentations. The course was interactive and aimed to teach and demonstrate facilitation skills as a methodology in the teacher training. The secondary school teachers were also given a basic manual providing the theory on the relevant topics as well as the activity sheets for interactive teaching. The approach to the course for implementation with learners was of a 
progressive nature. It started off with getting to know the target group (i.e., the teenage learners) and then moved on to issues that affect them. Specific topics addressed were how teenagers relate to issues in their inner and outer worlds - their home, community, classroom, and school. This sensitive exploration of how teenagers experience themselves eventually leads to topics and discussion related to HIV/AIDS and its impact on the individual, their immediate social network, and the community.

\section{Teacher training}

The teacher-training course was scheduled for five days. The master trainers coordinated the training for each of their regions. Consultants working in the area of change and transformation carried out the training in the Pietermaritzburg region, which was the study site. Teachers were selected by their respective schools from the criteria developed by the Department of Education. The training program was designed to take into account the realities of the school situation, for example, the time to implement the program. A single lesson per week was dedicated to implementing the program during the period allocated to the life-orientation learning area.

The training program for teachers covered the following broad areas:

- Life orientation learning area and outcome-based education

- Life skills focusing on HIV/AIDS

- Care and support of people living with AIDS

- Related issues, for example child abuse, substance abuse, and health promotion

- Skills development related to facilitation, project management, monitoring, and evaluation

The master trainers coordinated follow-up visits to provide support, guidance, and updated information to teachers in their areas. Despite the need for sexual education and the appropriateness of the school as a setting for such education, teachers are not traditionally equipped for this kind of teaching.

\section{In the classroom, teachers focused on HIV/AIDS information rather than on life skills.}

The teacher selected to attend the course was responsible for teaching the course to the learners in grade nine who were chosen for the study. The teacher was trained in the core curriculum but made the final decision about what to teach and how to teach it. When teachers were asked which course topics they had covered, most said they had covered seven of the eleven topics (Table 3), which were the sections of the curriculum that covered information about HIV/AIDS. They gave less attention to the life skills components of the course and to caring for people living with HIV/AIDS. Their emphasis on facts helps explain the greater improvement in the learners' knowledge than in their confidence and behavior. 
Table 3 Reported teacher coverage of program topics

\begin{tabular}{lrrrc}
\hline Topic & Yes & No & $\begin{array}{c}\text { Don't } \\
\text { know }\end{array}$ & $\begin{array}{c}\text { No } \\
\text { answer }\end{array}$ \\
\hline Understanding my body & 10 & & & 1 \\
My relationships with family, friends, and community & 9 & 1 & 1 & \\
Causes of HIVIAIDS & 10 & 1 & \\
Spread of HIVIAIDS & 10 & 1 & \\
Prevention of HIVIAIDS & 10 & 1 & \\
Living with people with AIDS & 9 & 2 & \\
Caring for people with AIDS & 7 & 3 & \\
Coping skills-decision making & 7 & 4 & \\
Coping skills-assertiveness & 7 & 3 & \\
Coping skills-communication & 7 & 3 & \\
Relationships (sexual) & 10 & 1 & & 1 \\
\hline
\end{tabular}

\section{Teachers' Satisfaction and Challenges}

Learner interest made teaching rewarding. When asked what was most satisfactory about teaching these sessions, most teachers mentioned learner interest and the importance of the topic. Teachers were satisfied that learners opened up, were relaxed, and were willing to discuss the issues in class. One teacher observed that these sessions helped students learn to communicate with each other about these topics. In addition, teachers received satisfaction from doing important work. As one teacher said, "I have saved some learners from possibly being victims of HIV/AIDS."

Teaching about sensitive topics presented special class management issues. Teachers reported several challenges to teaching the course. They felt unsure of the details of some topics and found some issues embarrassing, such as explaining the menstrual cycle. Learners wanted more information and were particularly interested in knowing the physiology of the opposite sex. One teacher, in fact, reported that the boys were "over enthusiastic" in learning about female physiology and needed to be referred for discussion after class.

According to the teachers, a small group of students were reluctant to participate in the class sessions. Some learners had difficulty expressing their opinions and feelings, even in structured lessons that called on them to comment on the actions of characters in a book or video. Other students believed in alternate explanations of HIV/AIDS and disagreed with the information given in class. In a few cases, teachers had to manage arguments among students about aspects of the disease. A few students did not value the course and the teacher found it difficult "trying to persuade them that it is relevant to them. They know the facts but feel that they know it all and 
...do not apply it to themselves." The same teacher noted that repeating the basic facts too often resulted in students resisting the subject and switching off.

Teachers need more information, training, and technical support. Most teachers requested more factual information about HIV/AIDS. They said that a health expert would have been able to give more complete explanations of some topics (e.g., the window period - the time it takes to produce antibodies that can be detected by an HIV test after becoming infected). One teacher mentioned wanting more information about people living with HIV/AIDS - what they need and how to care for them. Teachers mentioned that if they had more information they could be proactive in covering topics rather than reactive to learners' questions. 


\section{Conclusions and Recommendations}

The Life Skills Grade 9 Curriculum had a positive impact on students' knowledge of HIV/AIDS, attitudes about abstinence, and intention to use condoms. These effects are important for laying the groundwork for behavior change that will protect young people from HIV/AIDS. There was, however, no evidence of increased adoption of such protective behaviors as abstinence and condom use. This may be because the teachers did not focus as strongly on the life skills components as on provision of factual information on HIV/AIDS. Moreover this was the first time that the teachers had taught this particular curriculum. Their skills, comfort level, and effectiveness are likely to improve with experience.

\section{Programmatic Recommendations for Teacher Preparation and Support}

\section{Choose and train teachers who are committed to the program.}

The program requires strategies that are different from day to day teaching to be implemented effectively. It has to be delivered in a way that takes into account the individual learners' perceptions and sensitivity to the program. Teachers who are receptive to this will be more accommodating in their approach and able to manage the flexibility that such a program demands with confidence and ease. As indicated in this study, being able to meet the learners' needs enhances the teachers' feeling "of doing something" important and contributes to their feeling of satisfaction. Teacher choice therefore will always be crucial to the successful implementation of a like skills program focusing on HIV and AIDS.

\section{Provide teachers with moral, material, and technical support.}

The teachers who implemented the program indicated that they experienced problems with classroom management, learners' attitudes toward the discussions, and feeling ill-equipped to teach specific topics. On-going training, provision of updated materials and information, access and liaison with health professionals, and a forum to interact about the strengths and challenges of such a program need to be in place to ensure support to teachers. All of this will ensure the improvement in the quality of the program delivered as well as address the gaps indicated by both teachers and learners alike.

\section{Ensure dedicated time and prepared teachers to implement the program.}

The findings reflect that adequate classroom time and prepared teachers are needed to effect positive results from learners. Therefore it is essential that teachers be assured a space on the timetable and the necessary training and support to provide the program. This ensures that learners receiving the program will be adequately prepared to practice preventive behaviors that are 
necessary to keep them safe and avoid those behaviors that place them at risk. Teachers highlighted a need for more training in the areas of technical information about HIV and AIDS as well as about care and support of people living with HIV/AIDS.

\section{Provide a program that teaches skills as well as information.}

The findings reveal clearly that learners are adequately prepared with information that contributes to their day-to-day understanding of HIV and AIDS. But the findings also show that learners expressed a need for more skills to effect several variables, such as resistance to peer pressure, communication with their partner about sex, and negotiation and use of condoms. All of these are difficult tasks to accomplish and therefore require special skills on the part of the teacher. The classroom further enables a safe environment to provide such skills training and therefore training teachers to meet this need is a huge step toward bridging the gap between knowledge acquisition and behavioral practice.

\section{Programmatic Recommendations to Address the Needs of Learners}

- To strengthen the course to foster behavior change, more attention should be placed on helping teachers cover the life skills components and on responding to learners' desire for greater emphasis on resisting peer pressure and for talking to parents and partners about sex.

- Many learners were not sure that they could resist peer pressure and most requested more skills to resist pressure from friends. This is clearly an area in which learners feel vulnerable. Therefore a program that is focused on skill development and that allows for guided practice is needed.

- In revising the course, programmers can learn from both the students who gave positive responses and those who gave negative responses. In this study most learners liked the course and reported benefiting from it, but there was a group of learners who disagreed with each statement about the course. Data from this study and other sources can be used to identify both the groups of students who were satisfied and dissatisfied with aspects of the course. For example, a quarter of the learners found the course frightening, therefore the school program needs to address their fears.

- A fair percentage of learners were unsure of their feelings about the program and the need for such a program for themselves. This is a crucial finding to reflect on and address to ensure that most learners' needs are being met. Learner differences need to be taken into account with regard to, for example, sexual experience and activity, age and sex, and existing knowledge and perceptions of the issues related to HIV and AIDS. 


\section{Hgrizons}

\section{References}

Ajzen, I. 1991. "The theory of planned behavior," Organizational Behavior and Human Decision Processes 50: 179-211.

Bandura, A. 1986. Social Foundations of Thought and Action. Englewood Cliffs, NJ: PrenticeHall.

Breakwell, G.M., S. Hammond, and C. Fife-Shaw. 1995. Research Methods In Psychology. London: Sage Publications.

Department of Health (South Africa). 2000a. National HIV Seroprevalence Survey of Women Attending Public Antenatal Clinics in South Africa 1999. Pretoria, South Africa: Department of Health.

Department of Health (South Africa). 2000b. Draft National Integrated Plan for Children Infected and Affected by HIV/AIDS. Pretoria, South Africa: Department of Health.

Government of South Africa. 1999. Amendment to National Education Policy Act no. 27 of 1996, Government Gazette 410(20372): clauses 10-12,

http://www.polity.org.za/html/govdocs/notices/1999/not99-1927.html.

Markham, J. 1998. Evaluation Report: Teacher Training Project.

National Department of Education, South Africa. 1997. Curriculum 2005, Lifelong learning for the 21st Century. South Africa: Absolutely Media Marketing.

Reddy, M.V. 2002. Statistics For Mental Health Care Research. India: NIMHANS.

UNAIDS. 2000. Report on the Global HIV/AIDS Epidemic June 2000. Geneva: Joint United Nations Program on HIV/AIDS.

Varga, C. and B. Shongwe. 1999. School Based Reproductive Health Education. Durban: Health Systems Trust. 


\section{Hgrizons}

Horizons is a global operations research program designed to:

- Identify and test strategies to improve HIV/AIDS prevention, treatment, and care programs and services.

- Disseminate best practices and promote research utilization with a view toward scaling up successful interventions.

\section{(2) Population Council}

Horizons is implemented by the Population Council in collaboration with

- International Center for Research on Women (ICRW)

- International HIV/AIDS Alliance

- Program for Appropriate Technology in Health (PATH)

- Tulane University

- Family Health International (FHI)

- Johns Hopkins University

For more information, please contact:

Horizons Program, Communications Unit 4301 Connecticut Avenue, NW Suite 280 Washington, DC 20008 USA

Tel: 202-237-9400

Fax: 202-237-8410

Email:horizons@pcdc.org www.popcouncil.org/horizons 